\title{
Simultaneous determination of ciprofloxacin hydrochloride and metronidazole in spiked human plasma by ultra performance liquid chromatography-tandem mass spectroscopy
}

\author{
Ramzia El-bagary ${ }^{\mathrm{a}}$, Asmaa Ahmed El-Zaher ${ }^{\mathrm{b}}$, Ehab Elkady ${ }^{\mathrm{b}}$, Asmaa Abdelkerim Mandour ${ }^{\mathrm{a} *}$ \\ ${ }^{a}$ Future University in Egypt (FUE), 90 th Street, fifth settlement, New Cairo, Cairo 12311, Egypt. \\ ${ }^{b}$ Pharmaceutical Chemistry Department, Faculty of Pharmacy, Cairo University, Kasr El-Aini St., Cairo 11562, Egypt.
}

\begin{tabular}{|c|c|}
\hline ARTICLE INFO & ABSTRACT \\
\hline $\begin{array}{l}\text { Article history: } \\
\text { Received on: } 30 / 10 / 2015 \\
\text { Revised on: } 07 / 01 / 2016 \\
\text { Accepted on: } 16 / 02 / 2016 \\
\text { Available online: } 30 / 03 / 2016\end{array}$ & $\begin{array}{l}\text { Ciprofloxacin } \mathrm{HCl}(\mathrm{CIP}) \text { and Metronidazole (MET) are antibacterial drugs used in combination for treatment of } \\
\text { mixed aerobic/anaerobic infections. An UPLC-MS/MS method was developed for the simultaneous estimation } \\
\text { of CIP and MET in spiked human plasma using sildenafil citrate as an internal standard (IS). Protein } \\
\text { precipitation was used for analyte extraction. The chromatographic separation was completed within } 6 \mathrm{~min} \\
\text { using a mobile phase of } 0.1 \% \text { formic acid in water and acetonitrile }(70: 30, v / v) \text {, Zorbax C18, } 100 \times 4.6 \mathrm{~mm} \text {, }\end{array}$ \\
\hline $\begin{array}{l}\text { Key words: } \\
\text { Ultra high performance } \\
\text { liquid chromatography } \\
\text { Tandem mass spectroscopy } \\
\text { UPLC-MS/MS; } \\
\text { Ciprofloxacin; } \\
\text { Metronidazole; Human } \\
\text { plasma; Antibacterial agents; } \\
\text { Lower limit of quantitation } \\
\text { LLOQ. }\end{array}$ & $\begin{array}{l}\text { measured in the positive ion mode. Validation of the method showed standard curves to be linear in the range of } \\
10-4000 \mathrm{ng} \mathrm{mL} \mathrm{m}^{-1} \text { for CIP and } 30-12000 \mathrm{ng} \mathrm{mL}^{-1} \text { for MET with mean correlation coefficient exceeding } 0.999 \text {. In } \\
\text { human plasma, CIP and MET were stable for at least } 36 \text { days at }-70 \pm 5{ }^{\circ} \mathrm{C}, 6 \text { hours at ambient temperature and } \\
\text { after three freeze thaw cycles. After extraction from plasma, the samples were stable in auto sampler at } 22{ }^{\circ} \mathrm{C} \\
\text { for } 6 \text { hours. The method was simple, specific, sensitive, precise, accurate and suitable for bioequivalence and } \\
\text { pharmacokinetic studies. }\end{array}$ \\
\hline
\end{tabular}

\section{INTRODUCTION}

Ciprofloxacin, [1-cyclopropyl-6-fluoro-1,4-dihydro-4oxo-7-(piperazinyl)-quinolone-3-carboxylic acid] (Figure 1a) is a second generation fluoroquinolones member that showed an effective treatment for several systemic infections such as urinary, respiratory, gastrointestinal and cutaneous infections (Wilson et al., 2004). Fluoroquinolones are effective against both Gram-positive and Gram-negative bacteria by inhibiting bacterial DNA gyrase enzyme that leads to inhibition of bacterial DNA synthesis (Wilson et al., 2004). Ciprofloxacin $\mathrm{HCl}$ (CIP) is widely used due to its low toxicity as well as its very wide spectrum of antibacterial effect and low ability of causing bacterial resistance. Metronidazole (MET), [2-methyl-5nitroimidazole-1-ethanol] (Figure 1b), is an antiprotozoal, anti-

\footnotetext{
* Corresponding Author

Email: asmaa.mandour[at]gmail.com
}

amebic and antibacterial drug (Wilson et al., 2004). CIP and MET combination in pharmaceutical dosage forms is used for the treatment of mixed aerobic/anaerobic infections (Werk and Schneider, 1998). Several methods have been reported for the estimation of CIP in biological matrices. Those methods include HPLC operated with UV detection (Khan et al., 2012; Adib et al., 2008; Wu et al., 2008), with fluorescence detection (Ulu, 2011), (Muchohi et al., 2011; Watabe et al., 2010), Liquid chromatography/mass spectroscopy (Imre et al., 2010) and capillary electrophoresis (Bannefeld et al., 1997; Michalska et al., 2004). Similarly, a survey of analytical literature for the determination of MET in biological samples revealed methods based on UV detection using HPLC (Alhalabi et al., 2012), using HPLC-DAD (Ouyang et al., 2010) and LC coupled with tandem mass spectroscopy (Silva et al., 2009). CIP in admixtures with MET and ampicillin has been determined by NMR (Reinscheid, 2006). Also, MET in intravenous admixture with CIP has been 
determined by first-derivative spectrophotometry (Vega and Sola, 2001), second-derivative spectrophotometry (Mahrouse, 2012) and LC (Vega et al., 1999). The pharmacokinetics and serum bactericidal activities of CIP in combination with clindamycin or MET after intravenous administration in volunteers were studied (Deppermann et al., 1989). To the best of our knowledge, no method has been reported for the simultaneous determination of CIP and MET in human plasma using LC/MS/MS. Thus, the aim of the present work was to develop a highly selective and sensitive LC-MS/MS method with good precision and accuracy for the simultaneous estimation of CIP and MET in human plasma. Sildenafil citrate (Figure 1c) was used as an internal standard (IS). A detailed validation of analytical method was performed to yield reliable results. Moreover, the developed method could be successfully applied for further research as to assess the pharmacokinetic evaluation of CIP and MET in combination form.

\section{EXPERIMENTAL}

\section{Materials and reagents}

Pharmaceutical grade CIP and MET were supplied by MINAPHARM Pharmaceuticals (Cairo, Egypt) and certified to contain 100.70 and $99.44 \%$ respectively. Pharmaceutical grade sildenafil citrate (certified to contain 99.80\%) was supplied by Pfizer-Egypt. Acetonitrile HPLC grade, formic acid HPLC grade and methanol HPLC grade were all obtained from Sigma-Aldrich, Germany. Human plasma was obtained from VACSERA Blood Bank, Egypt. Deionized and purified water produced in-house from Millipore's Milli-Q System (USA) was used throughout the analysis.

\section{Instrument and conditions}

An Agilent ultra- performance liquid chromatographmass spectrometer (Germany), equipped with vacuum degasser, gradient quaternary pump VL, auto-sampler ALS, column oven TCC and Agilent (6460 Triple Quadrupole) LC-MS/MS System was used. Separation was carried out on a C18 column $(100 \mathrm{~mm} \times$ 4.6mm, 3.5 $\mu \mathrm{m})$ - Zorbax Eclipse Plus, USA. Data acquisition was performed using Agilent MassHunter Workstation software (B.03.01) and data processing was subsequently performed using MassHunter Quantitative analysis software (B.04.00).

Chromatographic elution was performed with a mobile phase consisting of $0.1 \%$ formic acid in water and acetonitrile (70: $30, v / v)$, pumped through the column at a flow rate of $0.5 \mathrm{~mL} \mathrm{~min}^{-}$ ${ }^{1}$. The column temperature was maintained at $30{ }^{\circ} \mathrm{C}$. Under these conditions, the retention times for CIP, MET and IS were around $1.99 \mathrm{~min}, 2.49 \mathrm{~min}$ and $4.89 \mathrm{~min}$, respectively (Figure 2a). The injection volume was $10 \mu \mathrm{L}$ and the injector needle wash solvent was methanol. The detector was operated in the positive ion mode for the detection of CIP, MET and IS. Multiple Reaction Monitoring (MRM) transitions measured at positive mode at $m / z 332.205 \rightarrow 314.0$ for CIP (Fig 1d), $m / z 171.97 \rightarrow 128.0$ for MET (Fig 1 e), and $\mathrm{m} / \mathrm{z} 475.1 \rightarrow 100.2$ for IS with a $20 \mathrm{~ms}$ dwell time of all drugs. The capillary voltage was set at $+4000 \mathrm{~V}$. The sheath gas flow was set at $9.0 \mathrm{~L} \mathrm{~min}^{-1}$ and temperature at $350{ }^{\circ} \mathrm{C}$ with nozzle voltage of $2000 \mathrm{~V}$. Collision energy was set at 20.0, 25.0 and $40.0 \mathrm{~V}$ for CIP, MET and IS respectively, while fragmentor voltage was set at $130 \mathrm{~V}$. Quantitation of the analytes in human plasma was based on the peak area ratio of cited drugs to IS.<smiles>O=C(O)c1cn(C2CC2)c2cc(N3CCNCC3)c(F)cc2c1=O</smiles>

(a)Ciprofloxacin

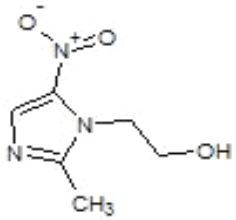

(b)Metronidazole

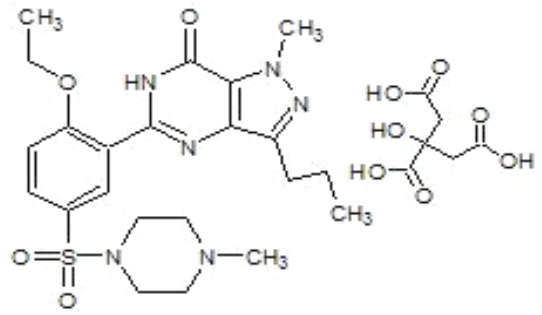

(c)Sildenafil Citrate
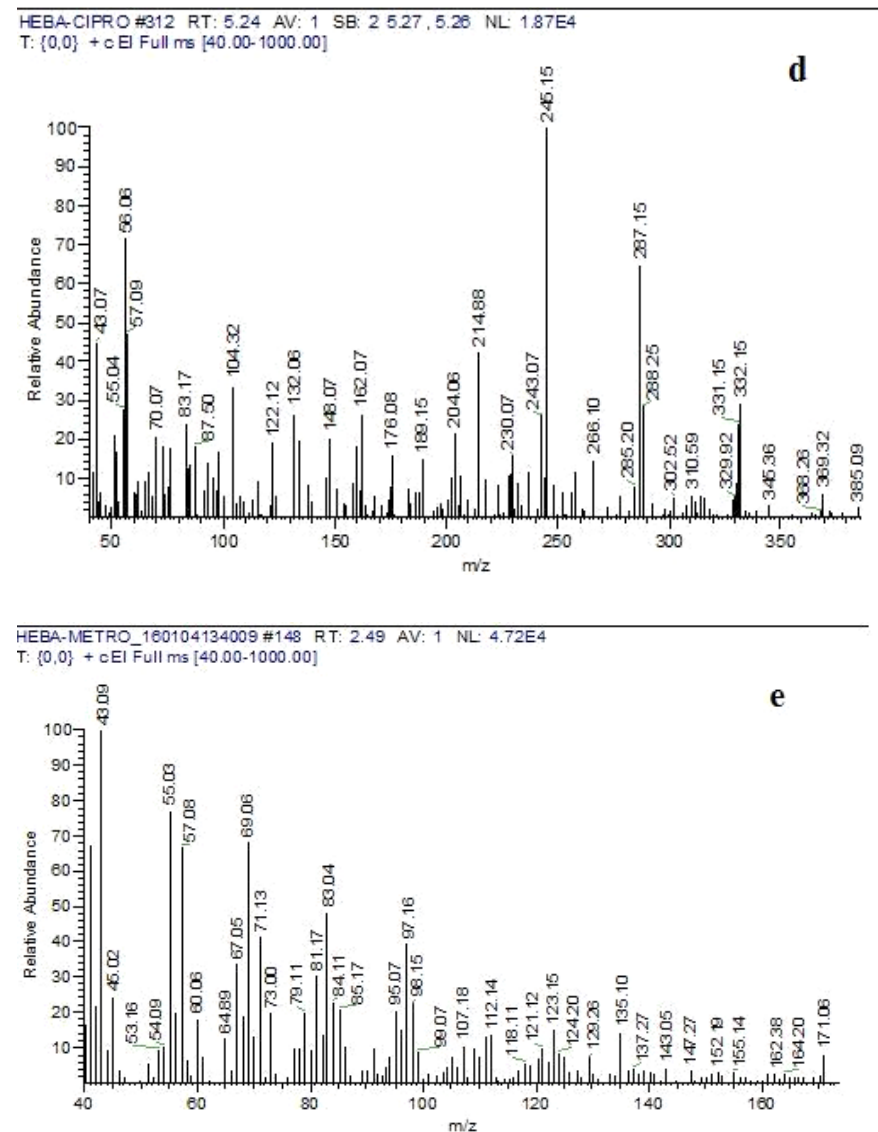

Fig. 1: Chemical structures of ciprofloxacin (a), metronidazole (b) and sildenafil citrate (c). Mass spectra of ciprofloxacin (d) and metronidazole (e). 

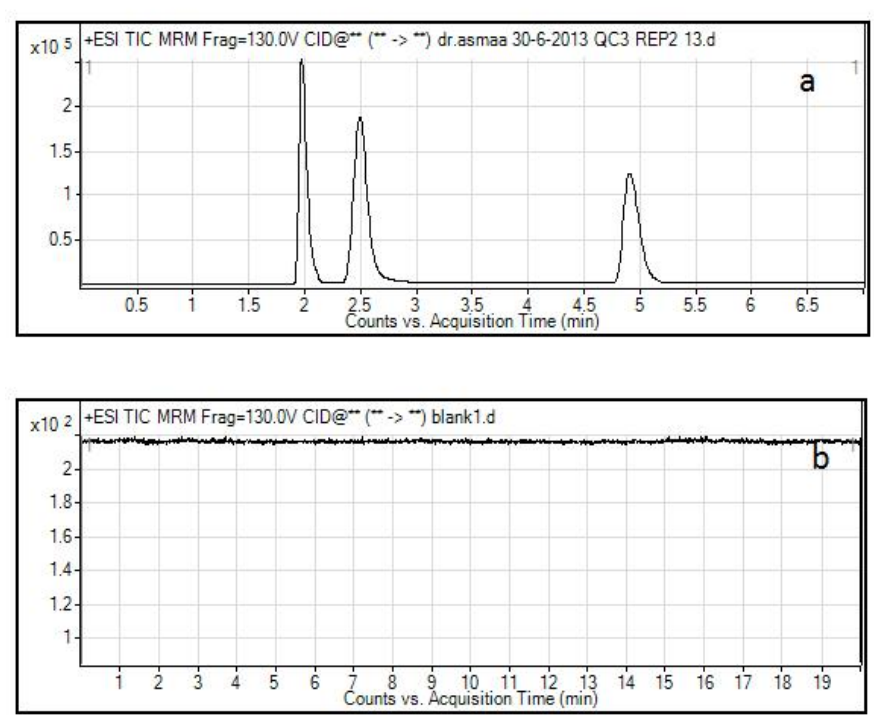

Fig. 2: (a) LC-MS/MS chromatogram of a $10 \mu \mathrm{L}$ injection of quality control high sample showing elution of ciprofloxacin (CIP) at $1.99 \mathrm{~min}$, metronidazole (MET) at $2.49 \mathrm{~min}$ and IS at $4.89 \mathrm{~min}$. (b) LC-MS/MS chromatogram of extracted blank plasma sample.

\section{Stock solution preparation}

Stock solutions of $100 \mu \mathrm{g} \mathrm{mL}^{-1}$ of CIP and both $(100 \mu \mathrm{g}$ $\mathrm{mL}^{-1}$ and $120 \mu \mathrm{g} \mathrm{mL}^{-1}$ ) of MET were separately prepared in methanol-water $(50: 50, v / v)$. Working solutions of CIP and MET were prepared by serial dilution of the corresponding stock solution with the solvent mixture. Also, IS was prepared in the same solvent mixture at concentration of $20 \mu \mathrm{g} \mathrm{mL}^{-1}$. All solutions were stored under refrigeration $\left(2-8^{\circ} \mathrm{C}\right)$ when not in use.

\section{Calibration samples and quality control samples preparation}

Eight non-zero calibration standards ranging from $10 \mathrm{ng}$ $\mathrm{mL}^{-1}$ to $4000 \mathrm{ng} \mathrm{mL}^{-1}$ for CIP and $30 \mathrm{ng} \mathrm{mL}^{-1}$ to $12000 \mathrm{ng} \mathrm{mL}^{-}$ ${ }^{1}$ for MET were prepared by adding $50 \mu \mathrm{L}$ of each known working solution of CIP and MET together, with $50 \mu \mathrm{L}$ of IS solution to $400 \mu \mathrm{L}$ of drug free human plasma. The quality control samples (QC) were prepared in the manner similar to the calibration standard at three concentration levels - low, medium and high (30, 1500 and $\left.3000 \mathrm{ng} \mathrm{mL}^{-1}\right)$ for CIP and (90, 5000 and $\left.10000 \mathrm{ng} \mathrm{mL}^{-1}\right)$ for MET, respectively.

All samples were vortexed to ensure complete mixing. During each run, six replicates of QC samples were extracted along with the calibration standards to verify the repeatability of the method.

\section{Sample preparation and extraction procedure}

Protein precipitation extraction was used, where $500 \mu \mathrm{L}$ of acetonitrile was added to $500 \mu \mathrm{L}$ of each spiked calibration plasma standard or QC sample. The solutions were then vortexed for $1 \mathrm{~min}$ and centrifuged at $4000 \mathrm{rpm}$, for $10 \mathrm{~min}$. The supernatant was transferred to a glass vial for LC-MS/MS analysis.

\section{Validation}

\section{Linearity}

To establish the linearity, a series of calibration standards of CIP and MET mixture (10, 25, 50, 100, 500, 1000, 2000 and $4000 \mathrm{ng} \mathrm{mL}^{-1}$ of CIP mixed with 30, 50, 150, 300, 1500, 3000, 6000 and $12000 \mathrm{ng} \mathrm{mL}^{-1}$ of MET, respectively were prepared by adding $50 \mu \mathrm{L}$ of the respective working solution of both CIP and MET together, and $50 \mu \mathrm{L}$ of a $20 \mu \mathrm{g} \mathrm{mL}^{-1}$ IS solution to $400 \mu \mathrm{L}$ of drug free human plasma and analyzed.

Five linearity curves containing eight non-zero concentrations were analyzed. A correlation of more than 0.99 was desirable. The lowest standard within the calibration curve was to be accepted as the lower limit of quantitation (LLOQ) if the analytes response in the standard was five times that of drug free (blank) plasma. In addition, the analyte peak in LLOQ sample should be discrete and reproducible with a precision of $\pm 20.0 \%$ and accuracy within $80.0 \%$ to $120.0 \%$. The deviation of standards other than LLOQ from the nominal concentration should not exceed $\pm 15.0 \%$. It is desirable that a minimum of six non-zero standards including LLOQ, met the above criteria.

\section{Specificity}

Six randomly selected drug free human plasma samples were processed by the similar protein precipitation extraction procedure and analyzed to determine the extent to which endogenous plasma components may interfere with analytes or internal standard.

\section{Recovery (extraction efficiency) from plasma matrix}

Recovery of CIP and MET were evaluated by comparing the mean peak responses of five measurements for each extracted quality control (QC) samples of each low, medium and high concentrations to mean peak responses of five unextracted standards of equivalent concentration. Similarly, the recovery of IS was also evaluated at the concentration of $2000 \mathrm{ng} \mathrm{mL}^{-1}$. The recovery of the analytes do not have to be $100.0 \%$, but the extent of recovery of an analyte should be consistent, precise and reproducible (fda.gov, 2004).

\section{Accuracy and precision (intra- and inter-day)}

Intra-day accuracy and precision were evaluated by sixreplicate analyses of CIP and MET mixture at concentrations of low, medium and high quality control (QC) samples in human plasma. The inter day accuracy and precision were assessed by analysis of low, medium and high quality control samples for CIP and MET on three consecutive days. The precision of the method was determined by calculating the percent coefficient of variation (CV\%) for the eighteen determinations obtained for each of the three QC concentrations. For the evaluation of precision, the deviation of each concentration level from the nominal concentration was accepted to be within $\pm 15.0 \%$ (except for LLOQ it is $\pm 20 \%$ ). Similarly, the mean accuracy should not deviate than $\pm 15.0 \%$ of the nominal concentration. 


\section{Stability}

Three aliquots of each, low and high QC samples were stored in a freezer at $-70 \pm 5{ }^{\circ} \mathrm{C}$ for 36 days. The samples were then processed and concentrations obtained were compared to nominal concentrations to predict the long-term stability of CIP and MET in human plasma.

In order to determine the short-term stability of plasma sample three aliquots each of the low and high-unprocessed QC samples were left at ambient temperature $\left(23-30^{\circ} \mathrm{C}\right)$ for 6.0 hours. After 6.0 hours the samples were processed, analyzed and compared with nominal concentrations. Auto-sampler stability was determined by analyzing three aliquots each of low and high QC samples that were processed before storing at $22{ }^{\circ} \mathrm{C}$ for 6.0 hours. After completion of 6.0 hours, samples were reanalyzed and concentrations compared with the freshly prepared control samples for cited drugs.

Effect of freeze and thaw cycles on stability of plasma samples after three freeze and thaw cycles was also determined. Three aliquots each of low and high-unprocessed quality control samples were stored at $-70 \pm 5{ }^{\circ} \mathrm{C}$ and subjected to three freeze thaw cycles. After the completion of third cycle, the samples were processed, analyzed and results were compared with nominal values.

All stability samples were considered stable if the deviation from the nominal concentration was within $\pm 15 \%$.

\section{RESULTS AND DISCUSSION}

The aim of the present investigation was to develop a sensitive and fast analytical method for the simultaneous determination and quantification of CIP and MET in human plasma. Based on the $\mathrm{C}_{\max }$ value of both cited drugs ( $3000 \mathrm{ng} \mathrm{mL}^{-}$ ${ }^{1}$ and $10000 \mathrm{ng} \mathrm{mL}^{-1}$, for CIP and MET respectively (Owens et al., 1997), (Ventura et al., 2008), a suitable linearity range of $10 \mathrm{ng}$ $\mathrm{mL}^{-1}$ to $4000 \mathrm{ng} \mathrm{mL}^{-1}$ for CIP \& $30 \mathrm{ng} \mathrm{mL}^{-1}$ to $12000 \mathrm{ng} \mathrm{mL}^{-1}$ for MET were selected. The use of conventional C18 column was suitable for optimum separation of CIP and MET when maintained at $30{ }^{\circ} \mathrm{C}$. Tandem mass spectrometric detection allowed the quantification of CIP and MET up to 10 and $30 \mathrm{ng} \mathrm{mL}^{-1}$ respectively.

The aim of the present work was to simultaneously determine both CIP and MET using an UPLC equipped with tandem mass spectrometer to attain higher sensitivity and selectivity for the detection and quantification of cited drugs in human plasma with a fast and cheap extraction process, allowing the method to be used in the pharmacokinetics evaluation of both drugs either alone or in combination.

\section{Method development}

During the optimization cycle, several chromatographic conditions were attempted using C18 column $(250 \mathrm{~mm} \times 4.6 \mathrm{~mm}, 5$ $\mu \mathrm{m})$ - Nucleosil and C18 column (100 mm×4.6 mm, $3.5 \mu \mathrm{m})-$ Zorbax Eclipse Plus. The use of C18 column with $3.5 \mu \mathrm{m}$ particle size of packing material under controlled temperature $\left(30{ }^{\circ} \mathrm{C}\right)$ column oven, achieved the desirable peak shape and elution of CIP, MET as well as for IS. Also, the use of a shorter column was of advantage giving a shorter run time, allowing faster batch analysis of human plasma samples.

Various mobile phase compositions were tried starting with acetronitrile and $10 \mathrm{mM}$ ammonium acetate with $0.1 \%$ formic acid in water that showed broadened peak of CIP. By changing the ratios of mobile phase contents, inconvenient broadend peaks were obtained over different flow rates and different formic acid ratios. While using a mobile phase composed of acetonitrile and ammonium acetate in different ratios, tailed broadened peak with inconvenient symmetry were observed. By trying different ratios of mobile phase consisting of acetonitrile and formic acid over different flow rates, it was found that $0.1 \%$ formic acid and acetonitrile in the ratio of 70:30 v/v using $0.5 \mathrm{~mL} \mathrm{~min}^{-1}$ flow rate gives the good results of sharp well resolved peaks with no overlapping. The use of $0.1 \%$ formic acid was to obtain higher detection response through assisting the ionization of cited drug molecules. For sample preparation, extraction methods including liquid-liquid and direct protein precipitation were studied. However liquid-liquid extraction using diethyl ether: dichloro methane mixture, 70:30 v/v gave poor recovery results of the analytes. The use of direct protein precipitation extraction method gave the advantage of achieving good sensitivity and fast processing of plasma samples with good recovery results.

\section{Bio-analytical method validation}

\section{Linearity and limit of quantitation}

Calibration curves for CIP and MET were constructed by plotting peak area ratio of cited drug to the internal standard versus the concentration of cited drug. The constructed calibration curves were found to be linear and precise over the linearity range of 10 $\mathrm{ng} \mathrm{mL} L^{-1}$ to $4000 \mathrm{ng} \mathrm{mL}^{-1}$ for CIP and $30 \mathrm{ng} \mathrm{mL}^{-1}$ to $12000 \mathrm{ng} \mathrm{mL}^{-}$ ${ }^{1}$ for MET. The lower limit of quantitation were $10 \mathrm{ng} \mathrm{mL}^{-1}$ and $30 \mathrm{ng} \mathrm{mL}^{-1}$ (lowest standard level) with accuracy of $118.29 \%$ and 99.49\% for CIP and MET, respectively. Results are presented in Table 1. The regression equation for each cited drug was also computed and the correlation coefficient was found 0.9995 and 0.9996 for CIP and MET, respectively. Back calculations were made from the calibration curves to determine accuracy of each calibration standard (Table 1).

Table 1: Summary of ciprofloxacin and metronidazole calibration standards in human plasma.

\begin{tabular}{|c|c|c|c|c|c|c|}
\hline \multicolumn{2}{|c|}{$\begin{array}{l}\text { Conc. of drug in } \\
\text { plasma }\left(\mathrm{ng} \mathrm{mL}^{-1}\right)\end{array}$} & \multicolumn{2}{|c|}{$\begin{array}{l}\text { Mean conc. Found } \\
\left(\mathrm{ng} \mathrm{mL} \mathbf{~ L}^{-1}\right)\end{array}$} & \multicolumn{2}{|c|}{ Accuracy } & \multirow[t]{2}{*}{$\mathbf{n}^{\mathrm{a}}$} \\
\hline CIP & MET & CIP & MET & CIP & MET & \\
\hline 10 & 30 & 11.82 & 29.84 & 118.29 & 99.49 & 5 \\
\hline 25 & 50 & 28.36 & 52.67 & 113.47 & 105.34 & 5 \\
\hline 50 & 150 & 55.75 & 150.17 & 111.5 & 100.11 & 5 \\
\hline 100 & 300 & 110.05 & 295.35 & 110.05 & 98.45 & 5 \\
\hline 500 & 1500 & 535.25 & 1529.32 & 107.05 & 101.95 & 5 \\
\hline 1000 & 3000 & 929.24 & 3091.71 & 92.92 & 103.05 & 5 \\
\hline
\end{tabular}




\begin{tabular}{|c|c|c|c|c|c|c|}
\hline 2000 & 6000 & 2006.42 & 5822.15 & 100.32 & 97.03 & 5 \\
\hline 4000 & 12000 & 4008.12 & 12058.69 & 100.2 & 100.48 & 5 \\
\hline \multirow{2}{*}{\multicolumn{2}{|c|}{$\begin{array}{l}\text { Mean correlation } \\
\text { coefficient }\end{array}$}} & CIP & \multicolumn{4}{|c|}{0.9995} \\
\hline & & MET & \multicolumn{4}{|c|}{0.9996} \\
\hline \multirow{2}{*}{\multicolumn{2}{|c|}{ Mean Intercept }} & CIP & \multirow{2}{*}{\multicolumn{4}{|c|}{$\begin{array}{l}0.0034 \\
0.0081\end{array}$}} \\
\hline & & MET & & & & \\
\hline \multirow{2}{*}{\multicolumn{2}{|c|}{ Mean Slope }} & CIP & \multicolumn{4}{|c|}{0.0005} \\
\hline & & MET & \multicolumn{4}{|c|}{0.0002} \\
\hline
\end{tabular}

a) n, number of determinations.

\section{Specificity}

There was no significant interference at the retention times for CIP, MET or IS from six different batches of drug free human plasma used for analysis (Figure 2a, b).

\section{Recovery (extraction efficiency) from plasma matrix}

The mean recovery for cited drugs in human plasma ranged between 74.73 to $85.67 \%$ and $70.49 \%$ to $78.31 \%$ for CIP and MET, respectively (Table 2). IS recovery from plasma was found to be $82.21 \pm 1.45$ (mean \pm SD, \%).

\section{Accuracy and precision (inter and intra-day)}

For CIP coefficient of variation for (Intra-day) was between $0.94 \%$ to $7.10 \%$ and the accuracy values were found to be between $91.00 \%$ to $107.70 \%$. Whereas, for MET coefficient of variation for (Intra-day) was between $0.47 \%$ to $5.77 \%$ and the accuracy values were found to be between $87.28 \%$ and $107.70 \%$. CIP inter-day accuracy ranged from $98.64 \%$ to $100.86 \%$ with coefficient of variation of $6.04 \%$ to $8.04 \%$, while MET inter-day accuracy ranged from $92.10 \%$ to $105.93 \%$ with coefficient of variation of $1.59 \%$ to $6.60 \%$. Results are presented in Tables 3a,b.

\section{Stability}

CIP and MET were stable at $-70 \pm 5{ }^{\circ} \mathrm{C}$ for at least 36 days (long term stability) in human plasma. The recovery percents in CIP concentration over the stability-testing period of 36 days in deep freezer at $-70 \pm 5^{\circ} \mathrm{C}$ were $97.10 \%$ and $90.04 \%$ of the concentrations from each of low and high quality control samples, respectively, while the recovery percents in MET concentration

Table 2: Recovery of ciprofloxacin and metronidazole from plasma.

\begin{tabular}{|c|c|c|c|c|c|c|c|}
\hline \multirow[t]{2}{*}{ QC sample } & \multicolumn{2}{|c|}{$\begin{array}{c}\text { Concentration of drug in plasma } \\
\left(\mathrm{ng} \mathrm{mL}^{-1}\right)\end{array}$} & \multicolumn{2}{|c|}{ Mean Recovery (\%) } & \multicolumn{2}{|c|}{$\mathrm{CV}(\%)^{\mathrm{a}}$} & \multirow[t]{2}{*}{$n^{b}$} \\
\hline & CIP & MET & CIP & MET & CIP & MET & \\
\hline Low & 30 & 90 & 74.73 & 70.49 & 1.24 & 0.38 & 5 \\
\hline Medium & 1500 & 5000 & 85.67 & 73.28 & 1.52 & 1.24 & 5 \\
\hline High & 3000 & 10000 & 79.83 & 78.31 & 0.8 & 1.01 & 5 \\
\hline
\end{tabular}

a) $\mathrm{CV}$, coefficient of variation; b) n, number of determinations.

Table 3a: Intra-day and inter-day results of ciprofloxacin in human plasma.

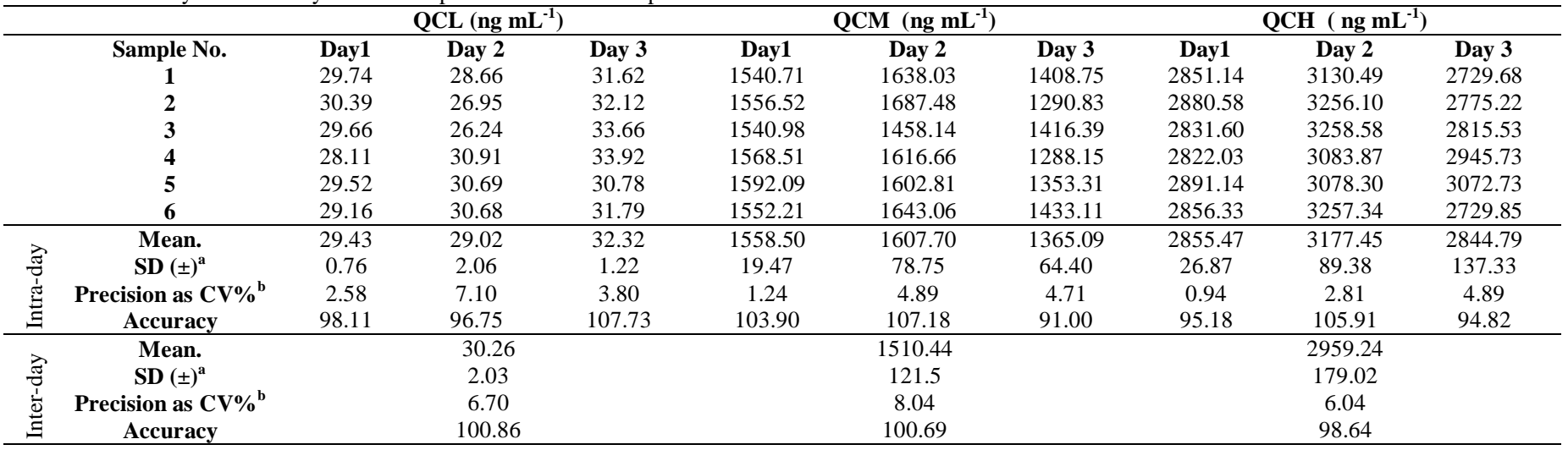

a) S.D., standard deviation; b) CV, coefficient of variation.

Table 3b: Intra-day and inter-day results of metronidazole in human plasma.

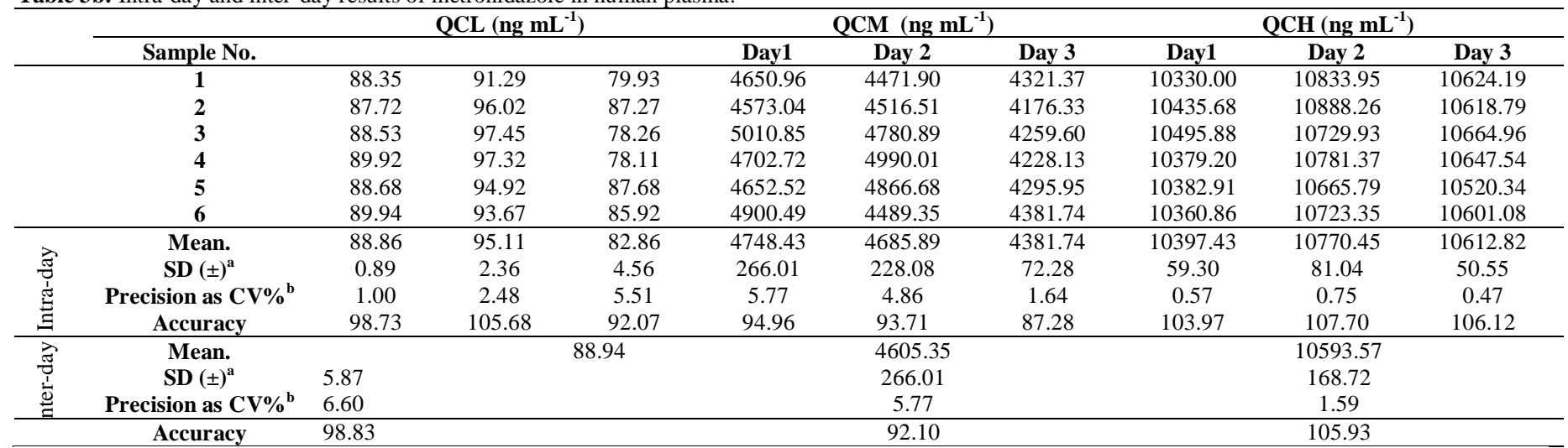

a) S.D., standard deviation; b) CV, coefficient of variation. 
Table 4a: Summary of stability data of ciprofloxacin in human plasma.

\begin{tabular}{|c|c|c|c|c|c|c|}
\hline Stability term & $\begin{array}{c}\begin{array}{c}\text { Conc. of CIP } \\
\left.\mathrm{mL}^{-1}\right)\end{array} \\
\end{array}$ & $\begin{array}{l}\text { Mean conc.of CIP found } \\
\left(\mathrm{ng} \mathrm{mL} \mathrm{L}^{-1}\right)\end{array}$ & S.D. $\pm^{a}$ & $\mathrm{CV}(\%)^{\mathrm{b}}$ & Stability (\%) & $\mathbf{n}$ \\
\hline \multirow{2}{*}{ Long term (36 days) } & 30 & 28.8 & 0.006 & 0.02 & 97.10 & 3 \\
\hline & 3000 & 2701.24 & 1.42 & 0.05 & 90.04 & 3 \\
\hline \multirow{2}{*}{ Short term (6 hours) } & 30 & 29.01 & 0.18 & 0.64 & 97.81 & 3 \\
\hline & 3000 & 2660.71 & 18.86 & 0.70 & 97.33 & 3 \\
\hline \multirow{2}{*}{ Auto-sampler (6hours) } & 30 & 29.29 & 0.18 & 0.61 & 98.73 & 3 \\
\hline & 3000 & 2722.04 & 7.49 & 0.27 & 99.57 & 3 \\
\hline \multirow{2}{*}{ Freeze and thaw } & 30 & 29.48 & 0.05 & 1.19 & 99.37 & 3 \\
\hline & 3000 & 2730.44 & 0.54 & 0.02 & 99.88 & 3 \\
\hline
\end{tabular}

a) S.D., standard deviation; b) CV, coefficient of variation; c) n, number of determinations.

Table 4b: Summary of stability data of Metronidazole in human plasma.

\begin{tabular}{|c|c|c|c|c|c|c|}
\hline Stability term & $\begin{array}{c}\text { Conc. of MET } \\
\left.\mathrm{mL}^{-1}\right)\end{array}$ & $\begin{array}{l}\text { Mean conc. of MET found } \\
\left(n g \mathrm{~mL}^{-1}\right)\end{array}$ & S.D. $\pm^{\mathrm{a}}$ & $\mathrm{CV}(\%)^{\mathrm{b}}$ & Stability (\%) & $\mathbf{n}^{\mathrm{c}}$ \\
\hline \multirow{2}{*}{ Long term (36 days) } & 90 & 85.53 & 0.68 & 0.80 & 96.60 & 3 \\
\hline & 10000 & 10159.17 & 50.33 & 0.49 & 98.34 & 3 \\
\hline \multirow{2}{*}{ Short term (6 hours) } & 90 & 87.71 & 0.09 & 0.1 & 99.07 & 3 \\
\hline & 10000 & 10218.25 & 43.73 & 0.42 & 98.91 & 3 \\
\hline \multirow{2}{*}{ Auto-sampler (6hours) } & 90 & 87.58 & 0.07 & 0.08 & 98.91 & 3 \\
\hline & 10000 & 10400.12 & 82.25 & 0.79 & 100.67 & 3 \\
\hline \multirow{2}{*}{ Freeze and thaw } & 90 & 86.81 & 0.32 & 0.37 & 98.04 & 3 \\
\hline & 10000 & 10458.29 & 37.06 & 0.35 & 101.24 & 3 \\
\hline
\end{tabular}

a) S.D., standard deviation; b) CV, coefficient of variation; c) n, number.

over stability-testing for same period under same freezing conditions were $96.60 \%$ and $98.34 \%$ of the concentrations from each of low and high quality control samples, respectively (Tables $4 a, b)$.

Both CIP and MET were found to be stable over 6.0 hours in human plasma at room temperature $\left(23-30{ }^{\circ} \mathrm{C}\right)$. The stability percents observed for CIP were $97.81 \%$ and $97.33 \%$ at the concentration of each of low and high quality control samples respectively, while the stability percents observed for MET were $99.07 \%$ and $98.91 \%$ under same conditions at the concentration of each of low and high quality control samples, respectively (Tables $4 \mathrm{a}, \mathrm{b})$. In the auto-sampler at $22{ }^{\circ} \mathrm{C}$, processed samples of CIP and MET were stable for 6.0 hours. Stability percents for samples after 6.0 hours for CIP were $98.73 \%$ and $99.57 \%$ at low and high quality control levels, respectively, while stability percents for samples at the same conditions for MET were $98.91 \%$ and $100.67 \%$ at low and high quality control levels, respectively. (Tables 4 a,b).

Frozen plasma samples containing both CIP and MET were found to be stable even after subjecting to three freeze-thaw cycles. The stability percent observed for CIP was $99.37 \%$ and $99.88 \%$ at low and high quality control levels studied, respectively. While the stability percent for MET after subjecting plasma samples to three freeze-thaw cycles was found to be $98.04 \%$ and $101.24 \%$ at concentrations of at low and high quality control samples, respectively (Table 4a,b).

\section{CONCLUSIONS}

The bio-analytical method presented in this manuscript was specific, sensitive accurate and precise enough to be applied to human clinical pharmacology, bioavailability, and bioequivalence studies requiring pharmacokinetic evaluation. The method required sample preparation by protein precipitation extraction with adequate recovery, followed by isocratic UPLC coupled with tandem mass spectrometric detection (LC-MS/MS). The LC-MS/MS method was rapid enough and capable of simultaneous estimating ciprofloxacin $\mathrm{HCl}$ and metronidazole up to 10 and $30 \mathrm{ng} \mathrm{mL}^{-1}$, respectively in human plasma with good accuracy and precision.

\section{REFERENCES}

Adib N, Shekarchi M, Kobarfard F, Hamedani MP, Hajimehdipoo $\mathrm{H}$ and Rahimifard $\mathrm{N}$. A new HPLC method for determination of ciprofloxacin in human plasma and its application in bioequivalence studies. Biosci. Biotechnol. Res. Asia, 2008; 5: 583-586.

Alhalabi Z, Al-Khayat MA and Haidar S. Separation and assay of antiprotozoal imidazole derivatives (Metronidazole, Tinidazole and Secnidazole) by RP-HPLC. Intl J Pharm Sci Rev Res, 2012; 13: 13-18.

Bannefeld KH, Stass $\mathrm{H}$ and Blaschke G. Capillary electrophoresis with laser-induced fluorescence detection: An adequate alternative to high-performance liquid chromatography, for the determination of ciprofloxacin and its metabolite desethylene ciprofloxacin in human plasma. J. Chromatogr B, 1997; 692: 453-459.

Deppermann KM, Boeckh M, Grineisen S, Shokry F, Borner K, Koeppe P, Krasemann C, Wagner J and Lode H. Combination effects of ciprofloxacin, clindamycin, and metronidazole intravenously in volunteers, Am. J. Med., 1989; 5A: 46S-48S.

Guidance for Industry: Bioanalytical Method Validation, U.S. Department of Health and Human Services, Food and Drug Administration Centre for Drug Evaluation and Research (CDER), Center for Veternary Medicine (CVM), 2004, http://www.fda.gov/cder/ guidance/index.htm.

Imre S, Vancea S, Dogaru G, Caldararu C, Vari CE and Dogaru MT. New liquid chromatography coupled with mass spectrometry method for ciprofloxacin monitoring in human plasma. Stud.Univ. tis. BabesBolyai Chem, 2010; 3: 65-74.

Khan MK, Khan MF, Mustafa G and Sualah M. Comparison of high-pressure liquid chromatography and microbiological assay for determination of ciprofloxacin tablet in human plasma employed in bioequivalence and pharmacokinetics study. Pak. J. Pharm. Sci., 2012; 25: 81-88. 
Mahrouse MA. Development and validation of a UV spectrophotometric method for the simultaneous determination of ciprofloxacin hydrochloride and metronidazole in binary mixture. $J$. Chem. Pharm. Res., 2012; 4: 4710-4715.

Michalska K, Pajchel G and Tyski S. Determination of ciprofloxacin and its impurities by capillary zone electrophoresis. $J$. Chromatogr A., 2004; 1051: 267-272.

Muchohi SN, Thuo N, Karisa J, Muturi A, Kokwaro GO and Maitland K. Determination of ciprofloxacin in human plasma using highperformance liquid chromatography coupled with fluorescence detection: Application to a population pharmacokinetics study in children with severe malnutrition. J. Chromatogr. B Anal. Technol. Biomed. Life Sci., 2011; 879: 136-152.

Ouyang LQ, Wu HL, Liu YJ, Wang JY, Yu YJ, Zou HY and Yu RQ. Simultaneous determination of metronidazole and tinidazole in plasma by using HPLC-DAD coupled with second-order calibration. Chin. Chem. Lett., 2010; 21: 1223-1226.

Owens JrRC, Patel KB, Banevicius MA, Quintiliani R, Nightingaleand $\mathrm{CH}$ and Nicolau DP. Oral bioavailability and pharmacokinetics of ciprofloxacin in patients with AIDS. Antimicrob. Agents Chemother., 1997; 41: 1508-1511.

Reinscheid UM. Direct determination of ciprofloxacin in admixtures with metronidazole and ampicillin by NMR. J. Pharm. Biomed. Anal., 2006; 40: 447-449.

Silva M, Schramm S, Kano E, Koono E, Porta V and Serra C. Development and validation of a HPLC-MS-MS method for quantification of metronidazole in human plasma. J. Chromatogr. Sci., 2009; 47: 781-784.

Ulu ST. Determination of ciprofloxacin in human plasma and urine by percolumn derivatization high performance liquid chromatography with fluorescence detection. Chin. J. Chem., 2011; 29: $1256-1260$.

Vega E, Dabbene V, Nassetta M and Sola N. Validation of a reversed-phase LC method for quantitative analysis of intravenous admixtures of ciprofloxacin and metronidazole. J. Pharm. Biomed. Anal., 1999; 21: 1003-1009.

Vega S and Sola N. Quantitative analysis of metronidazole in intravenous admixture with ciprofloxacin by first derivative spectrophotometry. J. Pharm. Biomed. Anal., 2001; 25: 523-530.
Ventura CJM, Alós A.M, Nomdedeu GJ, Merino SV and Salvador SJL. The pharmacokinetics of metronidazole and gentamicin in a single preoperative dose as antibiotic prophylaxis in colorectal surgery. Farm. Hosp., 2008; 32: 77-82.

Watabe S, Yokoyama Y, Nakazawa K, Schinozaki K, Hiraoka R, Takeshita K and Suzuki Y. Simultaneous measurement of pazufloxacin, ciprofloxacin, and levofloxacin in human serum by high-performance liquid chromatography with fluorescence detection. J. Chromatogr. B Anal. Technol. Biomed. Life Sci., 2010; 878: 1555-1561.

Werk R and Schneider L. Ciprofloxacin in combination with metronidazole. Infection, 1988; 16: 257-260.

Wilson CO, Gisvold O and Doerge RF. 2004. Textbook of organic medicinal and pharmaceutical chemistry, J. B. Lippincott-Raven: Philadelphia. pp.11.

Wu SS, Chein CY and Wen YH. Analysis of ciprofloxacin by a simple high-performance liquid chromatography method. J. Chromatogr. Sci., 2008; 46: 490-495.

\section{How to cite this article:}

El-bagary R, Elzaher AA, Elkady E, Mandour AA. Simultaneous determination of ciprofloxacin hydrochloride and metronidazole in spiked human plasma by ultra performance liquid chromatographytandem mass spectroscopy. J App Pharm Sci, 2016; 6 (03): 041047. 